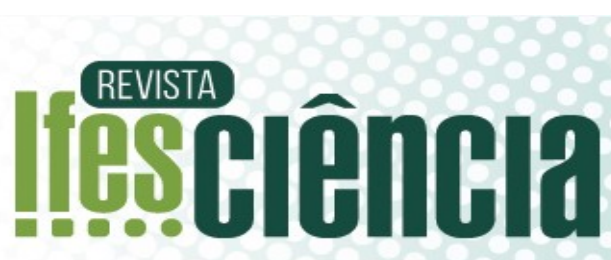

\section{FENÔMENO DAS ILHAS DE CALOR NA CIDADE DE COLATINA-ES E SANTA TERESA-ES}

\author{
PHENOMENOM OF THE URBAN HEAT ISLANDS IN COLATINA-ES \\ AND SANTA TERESA-ES
}

\author{
${ }^{1}$ Alexandre Cypreste Amorim* \\ ${ }^{2}$ Breno Fernandes Luchi \\ ${ }^{3}$ Gabriel Frasson Costa \\ ${ }^{4}$ Gabriel Zon Andrade de Assis \\ ${ }^{5}$ José Natal Lemos Thomaz \\ ${ }^{6}$ Murilo Salume Canni

\begin{abstract}
${ }^{1}$ Instituto Federal de Educação, Ciência e Tecnologia do Espírito Santo - Campus Colatina. E-mail: cypreste@ifes.edu.br

${ }^{2}$ Instituto Federal de Educação, Ciência e Tecnologia do Espírito Santo - Campus Colatina. E-mail: breno.fluchi@gmail.com

${ }^{3}$ Instituto Federal de Educação, Ciência e Tecnologia do Espírito Santo - Campus Colatina. E-mail: bielfc27@gmail.com

${ }^{4}$ Instituto Federal de Educação, Ciência e Tecnologia do Espírito Santo - Campus Colatina. E-mail: gabriel.zon.gz@gmail.com

${ }^{5}$ Instituto Federal de Educação, Ciência e Tecnologia do Espírito Santo - Campus Colatina. E-mail: josenatalemos@gmail.com muriloscanni@gmail.com *Autor de correspondência
\end{abstract} \\ ${ }^{6}$ Instituto Federal de Educação, Ciência e Tecnologia do Espírito Santo - Campus Colatina. E-mail:
}

Artigo submetido em 12/02/2020, aceito em 21/06/2020 e publicado em 28/08/2020.

Resumo: As ilhas de calor são fenômenos recorrentes em centros urbanos, causadas por diferença de ecossistemas, principalmente, pela ação antrópica do homem em construções, por impermeabilização do solo, redução de áreas arborizadas, aumento do número de veículos automotores, ares condicionados etc. O presente trabalho analisa esse fenômeno nas cidades de Colatina-ES e Santa Teresa-ES, o qual causa nas áreas urbanas um aumento na temperatura do ar, sensação e amplitude térmica em relação às áreas rurais, ou áreas que não são densamente urbanizadas, possuindo resquícios de vegetação e áreas livres (gramados, arbustos e árvores). A fim de avaliar o desempenho térmico dos diversos pontos escolhidos, foram realizadas medições com aparelhos eletrônicos, relatadas em planilhas e gráficos de forma a visualizar a variação de temperatura, média e desvio padrão das amostras de todos os locais. Após o tratamento dos dados, observou-se que o desempenho térmico nos centros urbanos foi pior em relação às áreas rurais livres e arborizadas. Tais problemas poderiam ser amenizados se houvesse a implantação de um planejamento específico para cada região da cidade, maiores áreas de circulação de vento, assim como o aumento da arborização local e permeabilização do solo, priorizando a presença de áreas livres, como por exemplo, parques, jardins, gramados etc.

Palavras-chave: Ilhas de calor; temperatura; clima urbano; Colatina; Santa Teresa.

Abstract: The Urban Heat Island (UHI) is a current phenomenon in urban areas, which is caused by the difference of ecosystems, but more importantly by human actions like constructions, soil 
waterproofing, reduction of arboreal areas, increasing of vehicles, air conditioner, etc. This article attempts to analyze an investigative way of the phenomenon, in Colatina - ES and Santa Teresa - ES, which causes an increase of air temperature, temperature and thermal amplitude sensation in urban areas compared to rural areas, or no-densely urban areas, this increase does not happen due to vegetation remnants and free areas (fields, bushes, and trees). To evaluate the thermal performance of the chosen spots, we carried out measurements with electronic devices, which were used to create spreadsheets and graphics for a view of temperature variations, an average and the standard deviation of all samples. After processing the data, it was possible to realize that the thermal performance in urban centers was worse, where there is a most significant presence of regions with greater constructive density and soil sealing than rural regions, which feature free and wooded areas. Such problems could be softened if there were the implantation of specific planning for each city region, larger areas of wind circulation, as the increase of the local afforestation and soil permeabilization, prioritizing the presence of free areas, for example, parks, gardens, lawns etc.

Keywords: heat islands; temperature; urban climate; Colatina; Santa Teresa.

\section{INTRODUÇÃO}

O crescimento populacional brasileiro e a urbanização, a partir da década 1960, colaboraram para o desenvolvimento do país. No entanto, esse processo não veio alicerçado, de forma simultânea, ao planejamento das cidades, o que levou a problemas como a impermeabilização do solo, falta de áreas de vegetação e densidades construtivas elevadas, tornando o ambiente urbano desagradável termicamente.

Nesse cenário, trazemos para nossos estudos o município de Colatina-ES, cuja criação, datada em 30 de dezembro de 1921 (COLATINA, 2018), obedeceu aos mesmos trâmites da falta de organização de ruas e bairros. Inicialmente, era povoado por imigrantes que habitavam as atuais regiões rurais do município. Já na década de 40 e 50, do século passado, ocorreu uma expansão da população urbana devido à Estrada de Ferro VitóriaMinas (EFVM), fato que contribuiu para um desenvolvimento mais a atender os propósitos desse investimento do que os cuidados necessários à construção de uma cidade que deveria ter sido planejada.

Essa realidade estruturou uma cidade cujo desempenho térmico - em uma análise empírica da situação - é descrito pelos próprios moradores como uma cidade quente, abafada em dias úmidos e com pouca circulação de ventos. Situação diferente analisada por moradores afastados do centro urbano, como os que vivem nos distritos do município, como Baunilha, Boapaba, São João Grande, entre outros, os quais possuem menor quantidade de edifícios, mais áreas livres e até mesmo zonas rurais com plantações e regiões de matas. Nesses locais, as sensações térmicas são mais agradáveis.

A literatura em geral aborda a questão de que a diferença de temperatura entre as regiões urbana e o entorno, sejam bairros afastados, distritos e zonas rurais, ocorre por causa do fenômeno das ilhas de calor (IC), o qual é provocado por ação antrópica.

Segundo Balchin e Pye (1947 apud OKE; STEWART, 2012), as IC são descritas como o aumento da temperatura dos centros urbanos em comparação ao seu entorno rural, porém esse conceito tornouse mais completo. De acordo com os autores, o conceito de urbano e rural é vago para uma análise científica, visto que o panorama das cidades mudou assim como o uso do solo. Portanto, uma IC pode ser descrita como a comparação da temperatura de um espaço urbano com seu entorno imediato, causada principalmente pelo acúmulo de calor dos materiais construtivos, alteração das condições naturais de utilização do solo e diferentes usos do espaço urbano, fatores que caracterizam a ação antrópica (BARROS; LOMBARDO, 2016). 
Partindo de estudos a respeito de IC, este estudo analisa esse fenômeno na cidade de Colatina-ES, espaço urbano, comparando-a com a cidade de Santa Teresa-ES que se destaca por áreas livres (gramados, arbustos e árvores). Nossa abordagem pautou-se em coletas de dados de temperaturas desses locais, correlacionando-as com as respectivas características ambientais de cada cidade.

\section{CLIMA E CIDADE}

A ocorrência do fenômeno das ilhas de calor no município de Colatina-ES é relatado por Meriguete (2017). Segundo a autora, os diferentes microclimas da cidade geram sensações de conforto térmico diferentes, devido à ação antrópica nos locais, por exemplo, ares condicionados, alta densidade construtiva, tráfego de veículos etc. Meriguete afirma, ainda, que os índices de desconforto em Colatina são maiores durante o dia, e em pontos de locais mais adensados o resfriamento à noite não ocorre de maneira expressiva, apresentando, nesses locais, uma baixa porcentagem de conforto em relação aos outros pontos. A região urbana apresenta uma elevação das temperaturas médias locais, o que em cidades de clima tropical, de acordo com Amorim et al. (2009), leva a uma intensificação do desconforto térmico, por elas já possuírem temperaturas do ar mais elevadas.

O sistema Köppen-Geiger, elaborado pelos climatologistas Wladimir Köppen e Rudolf Geiger em 1900, teve como objetivo padronizar as classificações climáticas de todas as regiões do planeta, categorizando os tipos climáticos por meio de um sistema de letras a partir de uma análise das temperaturas e pluviosidade. Diante disso, a região em que se encontra o município de Colatina pode ser definida como Aw, ou seja, clima tropical e estação seca no inverno, possuindo em um contexto global aspectos do Clima Tropical Semi-Úmido.

\subsection{ASPECTOS NATURAIS}

O clima na cidade de Colatina, mesmo descrito como Tropical Semi-Úmido, apresenta variações, devido a diversos fatores globais e regionais, como vegetação, continentalidade, umidade, relevo e massas de ar. Em primeira análise, a vegetação colatinense apresenta três tipologias principais, sendo essas a floresta ombrófila densa, floresta estacional semidecidual e a vegetação de Cerrado (ZAMBORLINI et al., 2017). Já as unidades geomorfológicas presentes são o Bloco Montanhoso Central, com menor frequência, e os Patamares Escalonados do Sul Capixaba, com maior periodicidade, ambos exprimem aspectos montanhosos, mas com suas diferenciações (COELHO et al., 2012).

Segundo Coelho (2009), houve um grande desmatamento florestal de forma mais intensa na unidade baixo Rio Doce com a utilização de técnicas rudimentares, para a construção de casas e rodovias, consequência do crescimento desordenado da cidade às margens do rio. Esse fato agravou de forma hidrográfica e climática a região, pois a falta da cobertura vegetal acarreta a redução das chuvas e volumes de lençóis freáticos, além do assoreamento dos rios e diminuição das nascentes, corroborando para um clima seco.

\subsection{CLIMA URBANO}

As cidades possuem características diversas, dentre elas, o clima, que pode sofrer influência de múltiplos fatores. $\mathrm{O}$ rápido crescimento e a falta de organização dos centros urbanos, além de muitas áreas impermeáveis, intensificaram as condições que contribuem para a formação de fenômenos que modificam o clima de uma determinada cidade (SILVA; FERREIRA; SANTOS, 2015). A morfologia urbana acaba promovendo um domínio sobre eventos os quais modificam a qualidade ambiental urbana. Por exemplo, as ilhas de calor e a dificuldade de escoamento de 
água de chuvas podem causar problemas como enchentes, desconforto térmico e poluição (ASSIS et al., 2007).

Vários autores concordam que o arranjo entre os edifícios e demais elementos urbanos, bem como a inércia térmica das superfícies são variáveis determinantes na mudança climática local, sobretudo na formação das ilhas de calor (ASSIS, 2005). Além disso, elas são estudadas por meio de coeficientes de ocupação (porcentagem do terreno ocupado pela projeção da edificação) e coeficientes de aproveitamento (relação entre área edificada e a área de terreno), que compreendem a densidade construída.

\subsection{ILHAS DE CALOR}

O fenômeno das IC urbana é caracterizado por Amorim et al. (2009) como sendo o aumento das temperaturas da área urbana da cidade, em relação às zonas urbanas periféricas ou zonas rurais, ocasionadas por fatores, como: localização da região, clima da região, tempo, industrialização, densidade das construções urbanas e tipos de materiais construtivos. Barros e Lombardo (2010, p.6) reafirmam a dualidade rural-urbano: "A ilha de calor urbana habitualmente é retratada como aumento da temperatura do ar dos ambientes urbanos em relação aos seus arredores".

Gartland (2010) aponta como principais causas das ilhas de calor a impermeabilização de superfícies, o emprego de materiais de pigmentação escura nas construções, a poluição do ar urbano, a verticalização das edificações, a falta de vegetação e o calor proveniente das atividades humanas. Esses fatores agem em diferentes proporções dependendo da região de estudo, relevo e condições meteorológicas.

Segundo Carlowicz (2009), o ecossistema em que a cidade está localizada também interfere para $\mathrm{o}$ aparecimento do problema. Em uma pesquisa feita pela NASA, foi constatado que "[...] áreas urbanas desenvolvidas em regiões áridas e semiáridas mostraram muito menos aquecimento comparados com os campos periféricos do que cidades construídas entre florestas e climas temperados" (CARLOWICZ, 2009, tradução nossa).

\subsection{MEDIDAS MITIGADORAS}

Quanto às medidas mitigadoras que podem ser adotadas, estas se dividem em três propostas: uma visa à mudança dos materiais construtivos adotados nas edificações; outra foca no planejamento urbano e nas questões ligadas à densidade construtiva; e, por último, a arborização das cidades e manutenção de índices mínimos de densidade foliar. Gartland (2010) trabalha a primeira e a terceira ideias em sua pesquisa, propondo soluções como: adoção de materiais de cobertura com maior albedo, refletindo mais a radiação solar e liberando calor acumulado mais rápido; mudança da cor dos pavimentos e maior permeabilidade desses; e o uso de árvores e vegetação rasteira para arrefecimento e aumento da umidade relativa do ar através da evapotranspiração.

Mudanças na própria legislação e organização das cidades podem ser realizadas, como, por exemplo, a inclusão dos aspectos de clima local, além de características de relevo, no Plano Diretor Municipal (PDM) de cada cidade, uma vez que as normas de recuos e iluminação tendem a ser similares em todo Brasil. Dessa forma, poderá ocorrer um afastamento entre a legislação e o clima local das cidades, uma vez que o país possui diversos domínios morfoclimáticos (ASSIS et al., 2007), tornando necessária a produção de PDM's específicos para cada cidade, para melhorar o conforto térmico.

Além disso, a utilização de telhados verdes pode ser uma alternativa eficaz para ambientes urbanos, porque o uso desse tipo de prática construtiva proporciona, durante 
o verão, a redução da temperatura superficial em $1.6^{\circ} \mathrm{F}\left[8.6^{\circ} \mathrm{C}\right]$ (FELLOWS, 2012) e ainda contribuir na retenção e escoamento de água. "Um telhado verde comum, de 4 a 6 polegadas de espessura [10 a $15 \mathrm{~cm}$ ], pode reter um galão [3,78 L] de água por pés quadrados $\left[0,09 \mathrm{~m}^{2}\right]$ do espaço do telhado" (FELLOWS, 2012, p. 4, tradução nossa).

Frota e Schiffer (2003) também destacam a importância da utilização de cores claras na pintura externa das edificações, o uso de materiais que absorvem pouca radiação solar e possa refleti-la o máximo possível, e ventilação natural nos edifícios, que refrescam o ambiente e renovam o ar, pela retirada de calor por convecção. Os benefícios do combate às ilhas de calor são muito maiores do que a promoção do conforto térmico, eles propiciam uma transformação na qualidade de vida de todos.

\section{PROCESSOS METODOLÓGICOS: MATERIAIS E MÉTODOS}

Para atingir os objetivos propostos, este estudo apresenta, inicialmente, uma revisão bibliográfica que consistiu em leituras e pesquisas de livros, monografias, dissertações, teses e artigos sobre as IC, a fim de embasar todo o conhecimento técnico-científico acerca do tema como: principais causas; estudos recentes em cidades de mesmo porte que Colatina; problemas atrelados ao tema e formas de mitigação do problema nos centros urbanos.

Visando averiguar a ocorrência de IC no centro urbano de Colatina, a segunda parte do estudo consistiu na coleta de dados de temperatura e umidade, com auxílio de dataloggers, modelo Itlog 80, marca Instrutemp (Figura 1), dos dias $1^{\circ}$ de setembro (domingo) a 14 de setembro (sábado) de 2019.
Figura 1: Equipamento de medição utilizado

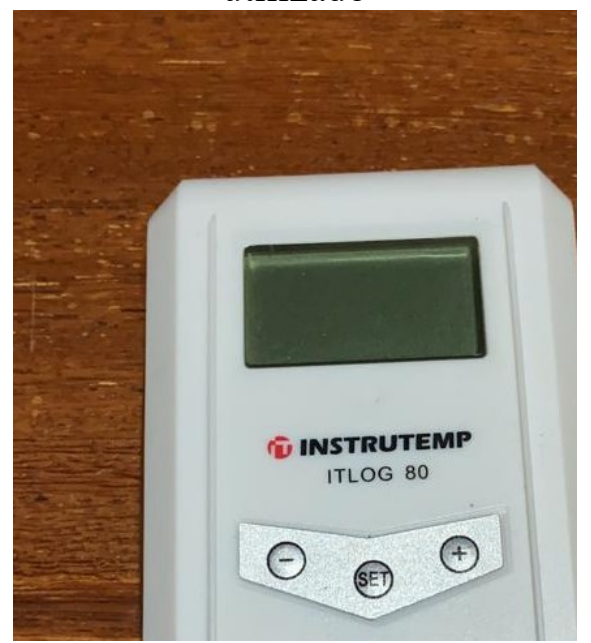

Fonte: Acervo dos autores (2019).

Almejando evitar interferências que poderiam danificar os aparelhos, como chuva e animais, os equipamentos foram inseridos em um abrigo utilizado no Laboratório de Tecnologias em Conforto Ambiental e Eficiência Energética (Latecae - UFV). O abrigo consiste em um cano de PVC em formato de "T" $\mathrm{e}$ envolvido em papel alumínio para se evitar a interferência dos raios solares diretos e se obter uma coleta mais eficiente da temperatura do ar ambiente (Figura 2).

Figura 2: Equipamento utilizado para proteção do medidor de temperatura

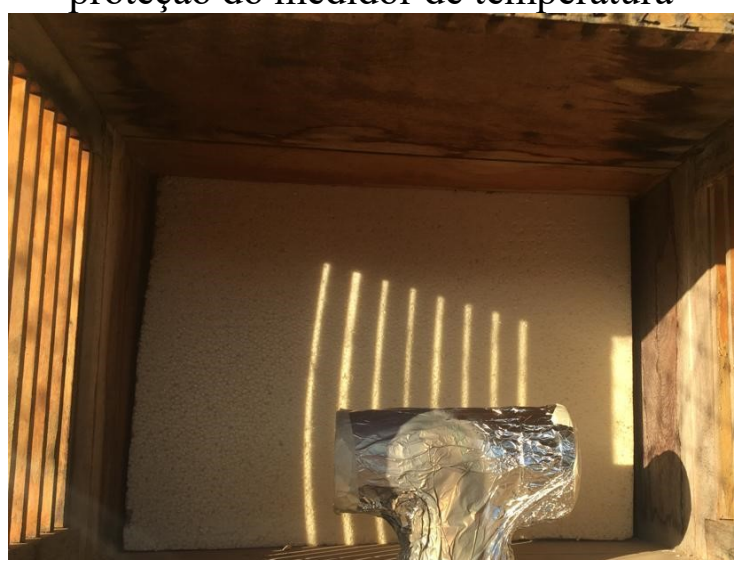

Fonte: Acervo dos autores (2019).

A localidade urbana definida para as medições foi a cidade de Colatina, localizada no centro do estado do Espírito Santo, no Vale do Rio Doce. Possui 
$1.398,219 \mathrm{Km}^{2}$ e aproximadamente 122.499 habitantes conforme IBGE (2019). De acordo com a Prefeitura da cidade, $88 \%$ da população vive na zona urbana e apenas $12 \%$ na rural. A topografia é ondulada, variando de 40 a 600 metros de altitude e uma temperatura média anual de $28^{\circ} \mathrm{C}$.

Colatina foi determinada como a cidade de análise, pois visa dar prosseguimento aos trabalhos desenvolvidos por Merigueti (2017) e Santos (2019), além de ampliar a base de pesquisa sobre essa temática em cidades de porte médio.

Os pontos urbanos escolhidos em Colatina (Figura 3) foram o bairro Centro (46m de altitude), região central do município, de intensa densidade construtiva; bairro Marista $(41 \mathrm{~m}$ de altitude), residencial e próximo a corpos hídricos; bairro Moacir Brotas (158m de altitude), também residencial; Ifes Campus Colatina ( $76 \mathrm{~m}$ de altitude), localizado no bairro Santa Margarida, residencial, mas de baixa ocupação (GOOGLE).

Figura 3: Pontos escolhidos na cidade de Colatina

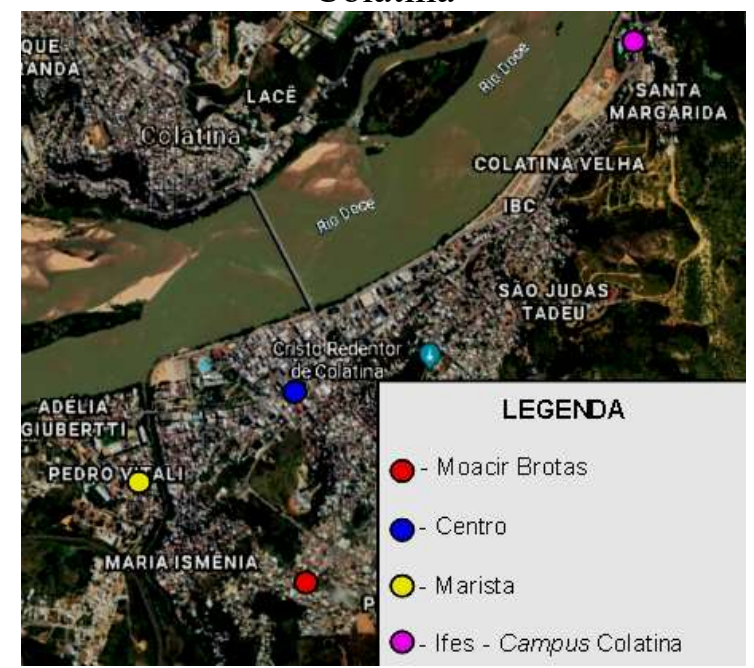

Fonte: Google Map (2019).

As localidades rurais escolhidas para comparações com o centro urbano de Colatina foram o distrito de São João de Petrópolis e a comunidade de São Pedro Frio (Figura 4), distantes $31 \mathrm{~km}$ e $24 \mathrm{~km}$, respectivamente. São João de Petrópolis é pertencente à Santa Teresa, localizado na região serrana do estado do Espírito Santo e possui $683.219 \mathrm{Km}^{2}$, população de aproximadamente 23.590 habitantes segundo IBGE (2019). Consoante com a Prefeitura, Santa Teresa possui $38 \%$ de matas nativas e capoeiras em regeneração. Já a comunidade de São Pedro Frio pertence à Colatina, sendo caracterizada como uma região produtora de uva, café e tomate, com alta presença de corpos hídricos e altitude de 470m (GOOGLE).

Figura 4: Pontos rurais escolhidos e Colatina

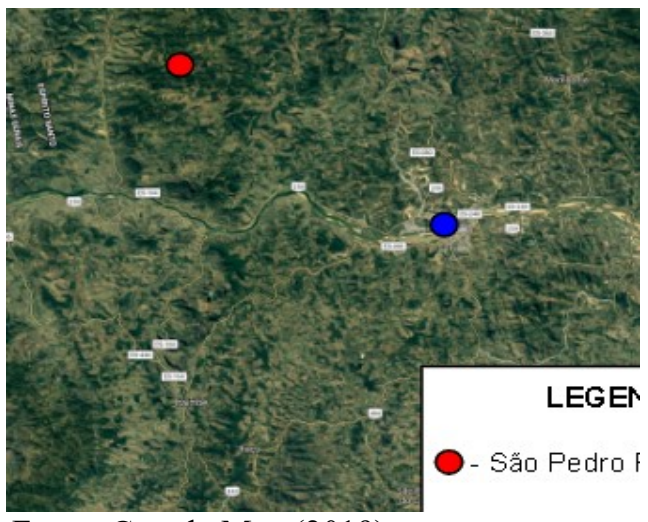

Fonte: Google Map (2019).

Após a coleta de dados, as informações foram tratadas em planilhas eletrônicas, contendo as análises de temperatura de cada dia e de todos os locais, além de tomada de informações estatísticas sobre o desempenho térmico de cada localidade, como média, moda, mediana, desvio padrão e variância da amostra.

\section{RESULTADOS E DISCUSSÕES}

A análise inicia-se na localidade de Colatina. O Ifes Campus Colatina apresentou temperaturas entre $18.5^{\circ} \mathrm{C}$ e 35 ${ }^{\circ} \mathrm{C}$, e uma média de $25.24{ }^{\circ} \mathrm{C}$ (Gráfico 1 ). Já as temperaturas do bairro Marista tiveram mínima de $19.60{ }^{\circ} \mathrm{C}$ e máxima de $33.10^{\circ} \mathrm{C}$ e uma média de $25.63^{\circ} \mathrm{C}$ (Gráfico 2). Em Moacir Brotas, as máximas e mínimas mantiveram-se próximas das últimas localidades, em $33.30^{\circ} \mathrm{C}$ e $19.9^{\circ} \mathrm{C}$ 
respectivamente e a média foi $25.67{ }^{\circ} \mathrm{C}$ (Gráfico 3). São João de Petrópolis (Gráfico 4) e São Pedro Frio (Gráfico 5) apresentaram as temperaturas mais baixas dentre todas as medições. No distrito teresense, as mínimas e máximas foram $16.3{ }^{\circ} \mathrm{C}$ e $35.9^{\circ} \mathrm{C}$ e em São Pedro, $15.5^{\circ} \mathrm{C}$ e $32.5^{\circ} \mathrm{C}$, além de as menores médias, 24.6 ${ }^{\circ} \mathrm{C}$ em Santa Teresa e $21.67^{\circ} \mathrm{C}$ no distrito Colatinense.

Gráfico 1: Temperaturas medidas no Ifes - Campus Colatina

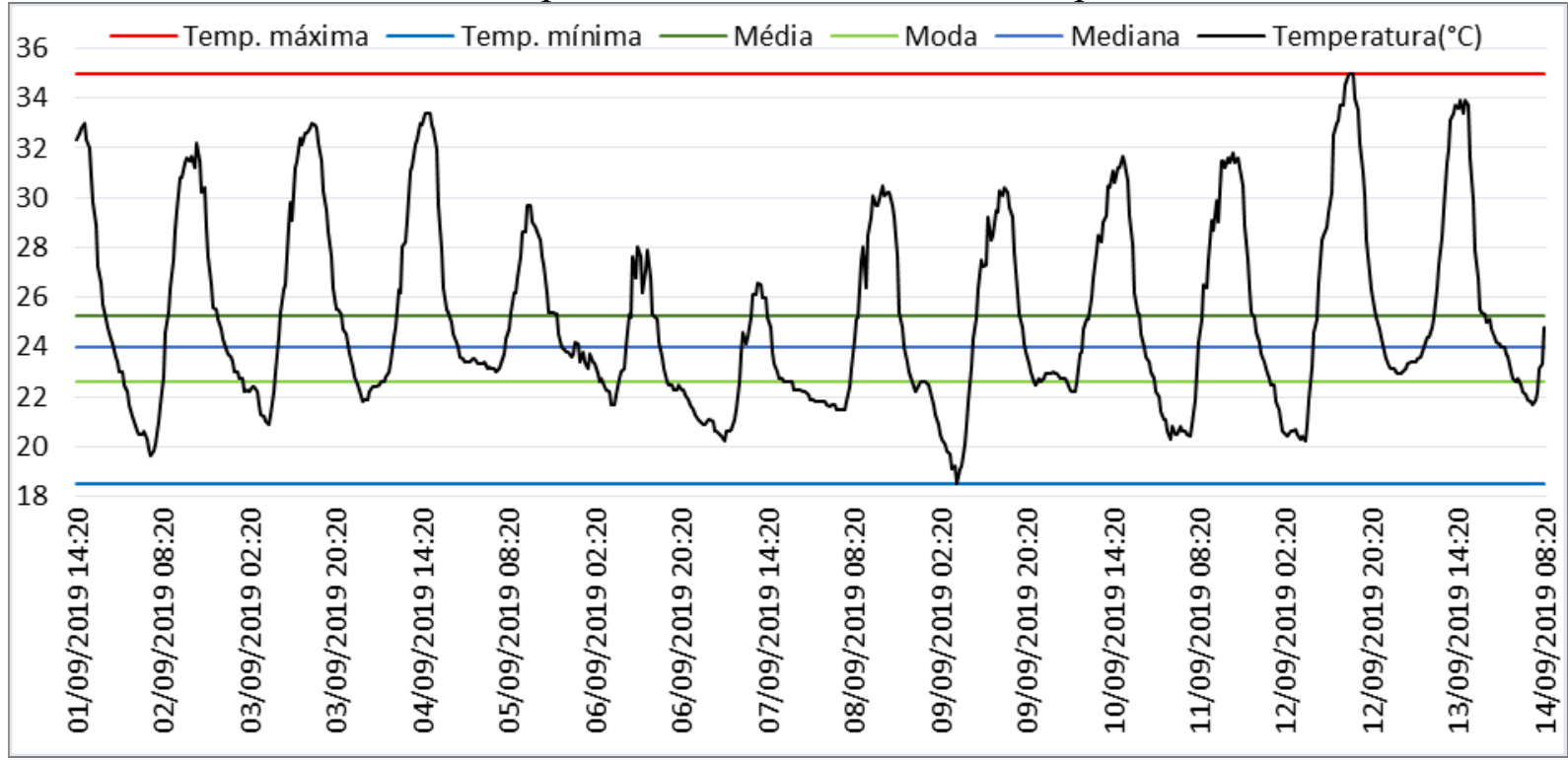

Fonte: Elaborado pelos autores.

Gráfico 2: Temperaturas medidas no bairro Marista

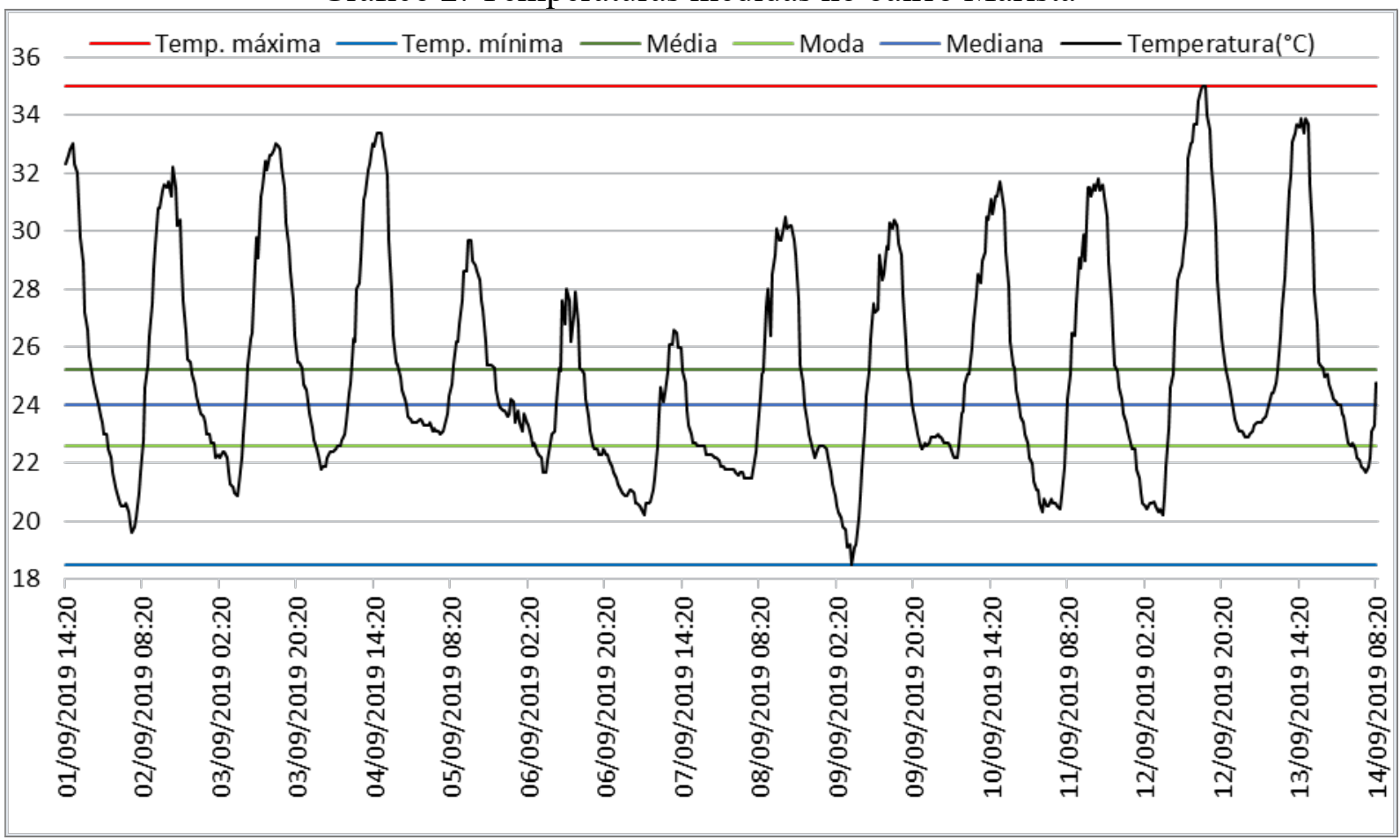

Fonte: Elaborado pelos autores. 
Gráfico 3: Temperaturas medidas no bairro Moacir Brotas

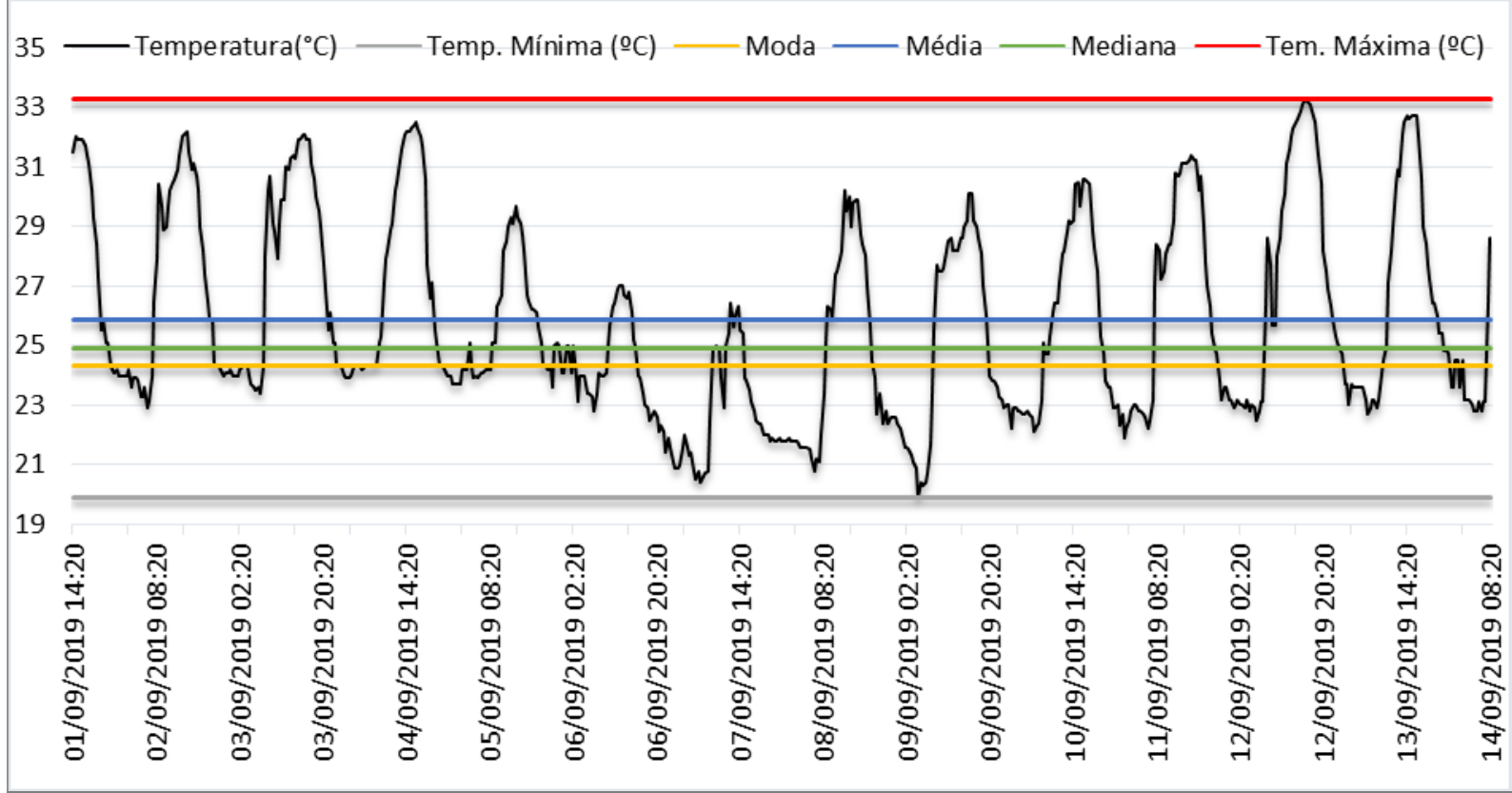

Fonte: Elaborado pelos autores.

As temperaturas de todos os locais se mantiveram próximas ou com pequenas variações de máxima e mínima. Logo, com essa amostra, o desvio padrão seria bem pequeno. Porém, o centro de Colatina apresentou uma grande discrepância em relação aos outros pontos, tendo $46.2^{\circ} \mathrm{C}$ de máxima e $20.3{ }^{\circ} \mathrm{C}$ de mínima, resultando em uma temperatura média de $28.62{ }^{\circ} \mathrm{C}$.

Gráfico 4: Temperaturas medidas em São João de Petrópolis

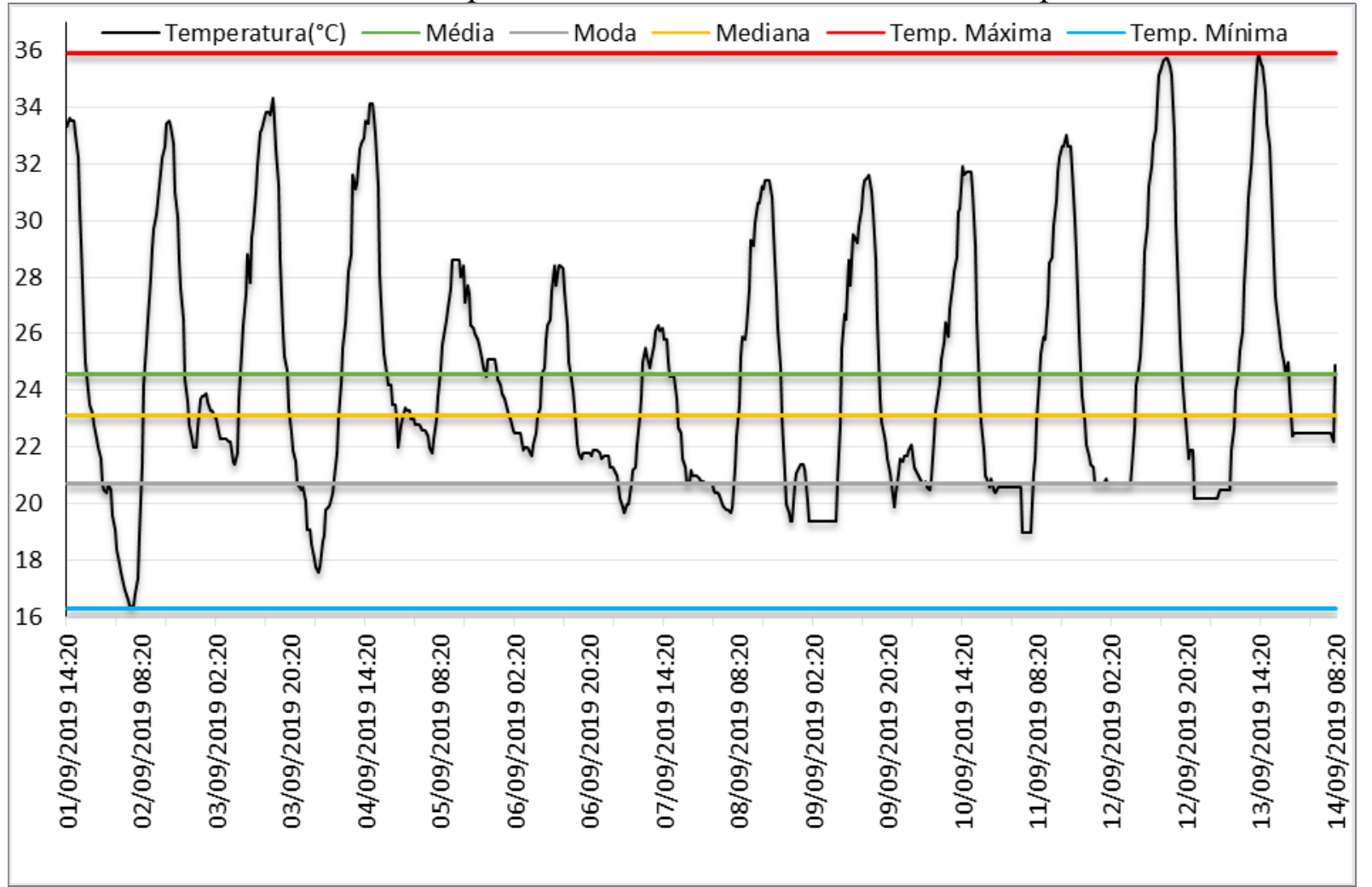

Fonte: Elaborado pelos autores. 
Gráfico 5: Temperaturas medidas em São Pedro Frio

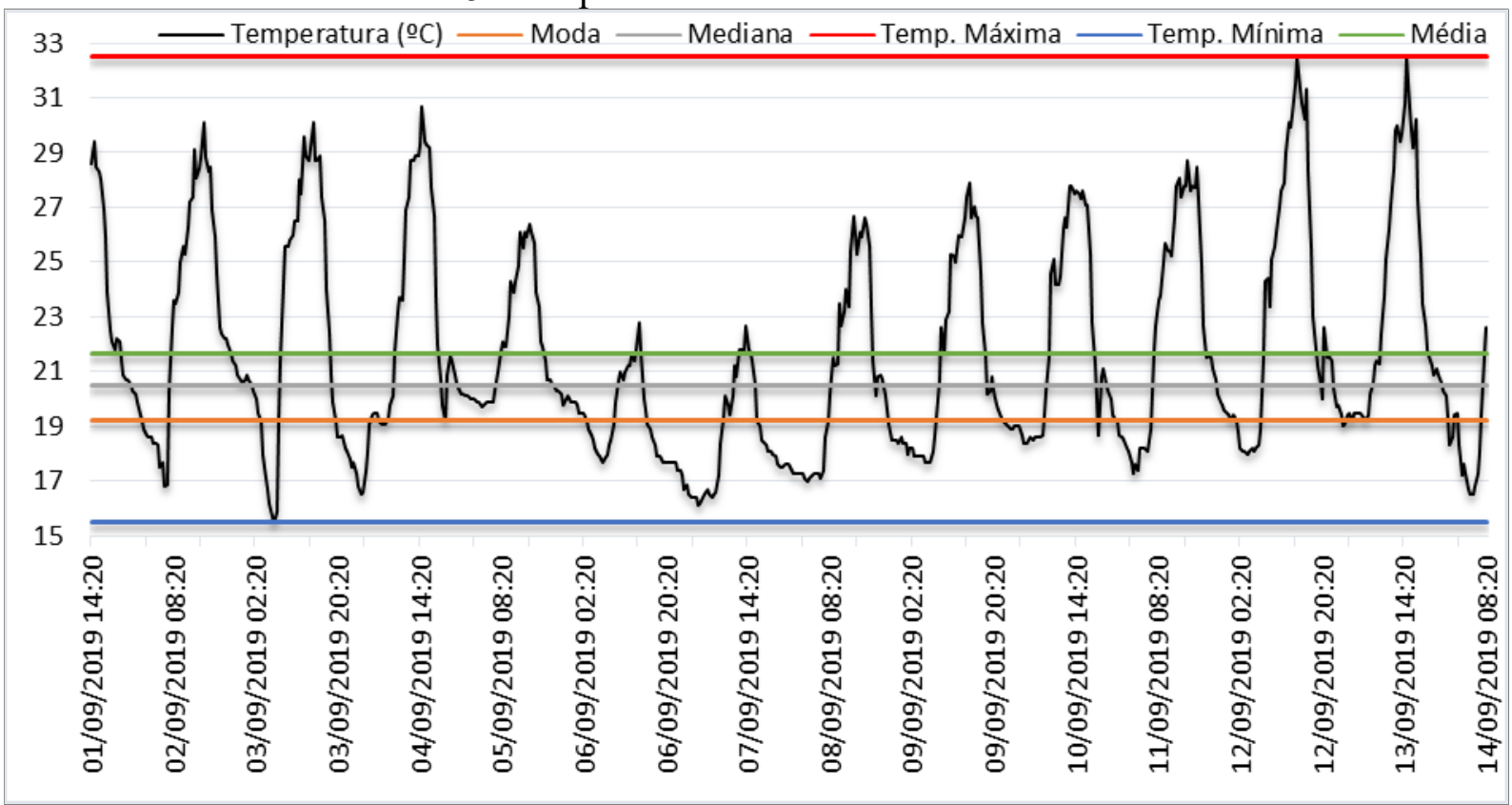

Fonte: Elaborado pelos autores.

Apenas comparando as temperaturas médias do Centro (Gráfico 6) com os outros bairros é possível perceber variações de até $7^{\circ} \mathrm{C}$. É possível concluir, também, que o dia mais quente desse período foi o dia 12 de setembro de 2019 e o mais frio 07 de setembro de 2019. Após a análise individual do desempenho térmico de cada região, foi feito o estudo geral, comparando todas as localidades (Gráfico 7).

Gráfico 6: Temperaturas medidas no Centro de Colatina

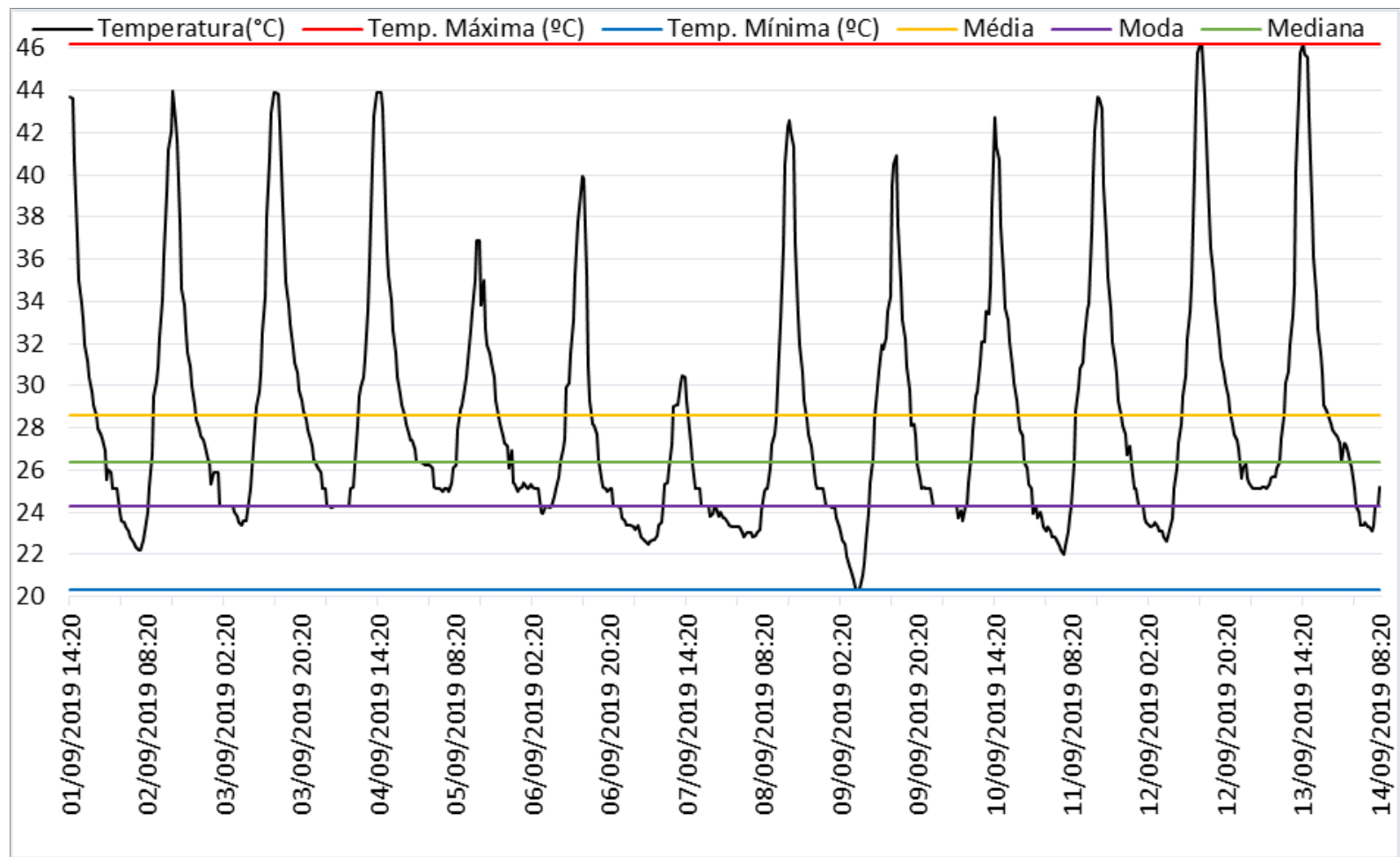

Fonte: Elaborado pelos autores. 
Gráfico 7: Comparativo geral das temperaturas

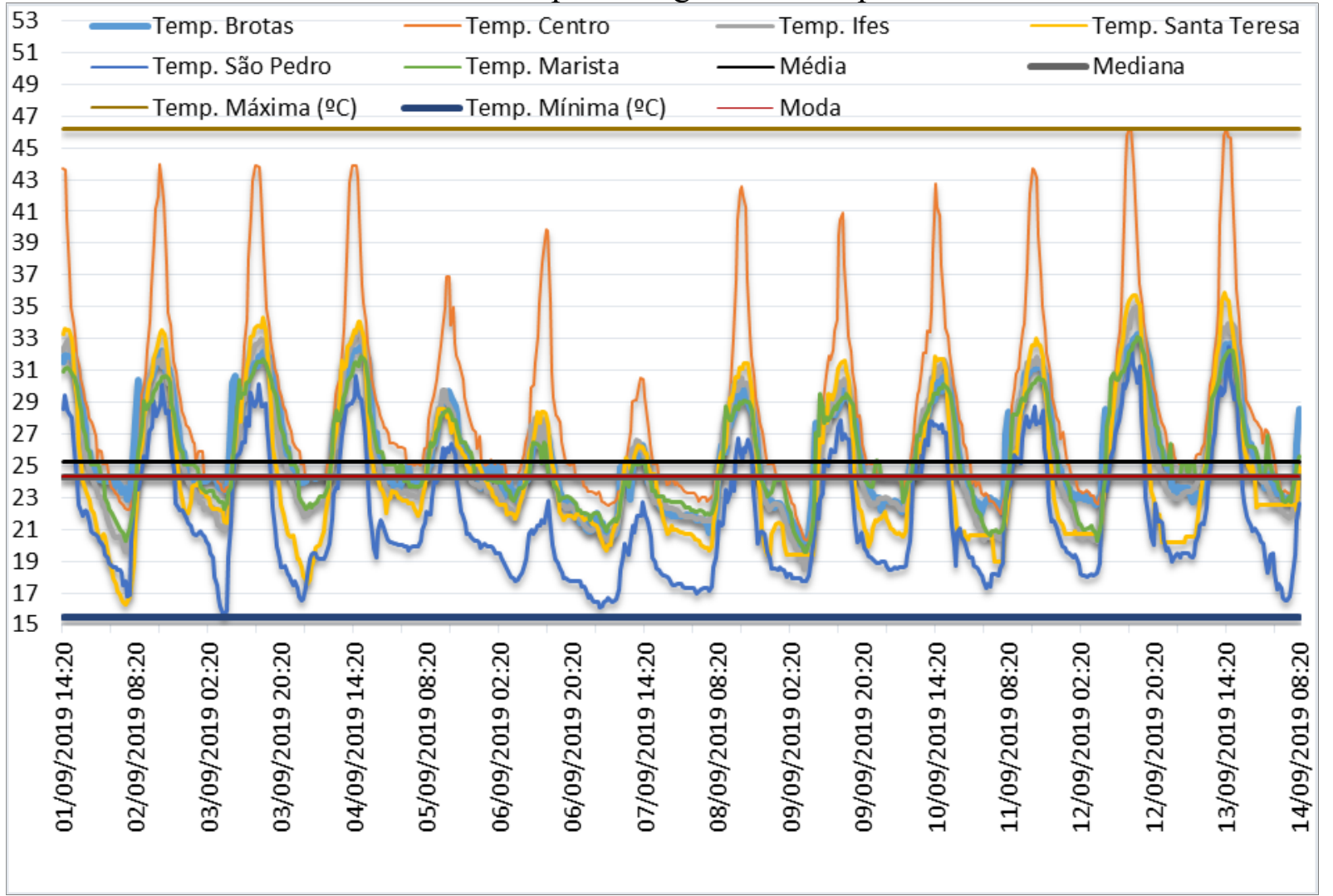

Fonte: Elaborado pelos autores.

Dentre os motivos que tornam o Centro o local mais quente são: o grande adensamento construtivo, que prejudica a circulação de vento, uma vez que muitas passagens são bloqueadas e não há a formação de corredores de ventilação; o grande número de ares condicionados, cujas condensadoras liberam uma grande quantidade de calor para fora dos edifícios; pequena quantidade de áreas arborizadas, existindo apenas entre as pistas da Avenida Getúlio Vargas; a abundância de veículos que circulam durante o dia e a noite nessa região, além de grandes áreas aterradas próximas ao Rio Doce.

Diferentemente da região mais quente analisada, São Pedro Frio e São João de Petrópolis se mostraram com um melhor desempenho térmico porque apresentam áreas livres, com uma densidade de construções muito menor do que os centros urbanos. Logo, a ventilação ocorre mais facilmente, além de serem arborizados (apesar da agropecuária ter cada vez mais espaço que a mata nativa). São João de Petrópolis apresenta outra característica que possibilita um maior conforto térmico, que é estar localizado em uma região de maior altitude do que o município de Colatina, assim como São Pedro Frio.

Os outros pontos apresentaram regularidade de temperatura e amplitude térmica, com valores de média muito próximos entre eles, de variação de menos de $1{ }^{\circ} \mathrm{C}$. No Ifes, a média foi de $25.24{ }^{\circ} \mathrm{C}$, Moacir Brotas apresentou valor de 25.86 ${ }^{\circ} \mathrm{C}$ e Marista, $25.63{ }^{\circ} \mathrm{C}$. O Ifes e o Brotas estão localizados em áreas mais afastadas do centro e mais altas e essa distância causou uma grande variação em comparação com os extremos da área com pior desempenho térmico, porque $\mathrm{o}$ campus possui uma área arborizada em seu entorno e a própria arquitetura do edifício propicia uma ventilação adequada. Já o bairro Moacir Brotas, além de ser afastado e mais alto, possui ruas largas, poucas construções altas e menor densidade de 
edificações. O último ponto, o bairro Marista, é próximo do Centro. Sendo assim, os resultados deveriam ser semelhantes a essa região, porém os dados mostraram o contrário, principalmente pela presença do Rio Santa Maria que corta o bairro e deságua no Rio Doce, atrás do ponto escolhido para a coleta.

\section{CONCLUSÕES}

A partir dos resultados, foi possível verificar a presença do fenômeno das ilhas de calor, principalmente no Centro de Colatina, o que gera situações de desconforto térmico para as pessoas. Nos limites da cidade de Colatina, constata-se que o problema foi maior no período do dia e amenizado durante a noite, quando não se tem a radiação solar sobre as superfícies. Isso ocorreu em todos os pontos, inclusive no centro da cidade, onde foram medidas as temperaturas mais altas e a maior amplitude térmica.

Observa-se que a principal causa desse problema é a ação antrópica, já que na região de pior desempenho há um grande número de condensadoras de arescondicionados, tráfego intenso, pouca arborização, solo impermeabilizado, cores escuras que absorvem maior radiação solar nas fachadas e, sobretudo, uma alta densidade construtiva. Todos esses fatores podem contribuir para o agravamento do problema, principalmente durante o dia, mais precisamente no início da tarde, por volta das 14 horas, período das temperaturas mais elevadas.

Nos locais mais afastados dos centros urbanos, conclui-se que o desempenho térmico foi melhor, porque as áreas livres e arborizadas são maiores, a densidade construtiva é baixa, visto que se encontram na zona rural e as casas são esparsas, o tráfego é quase nulo, a há presença de recursos hídricos, além de estarem localizadas em altitudes maiores do que a maioria dos pontos na cidade de Colatina.
Quanto aos bairros Moacir Brotas, Marista e o Instituto Federal, apesar de estarem localizados na zona urbana, apresentaram um desempenho mais próximo das regiões rurais do que do centro da cidade, principalmente por permitirem a passagem de correntes de vento. Todos eles tiveram temperaturas mínimas abaixo de $20^{\circ} \mathrm{C}$ e suas médias foram todas por volta de $25^{\circ} \mathrm{C}$, o que mostra regularidade nessas regiões e evidencia que o Centro sofre com o problema que deve ser amenizado.

A relação entre as áreas periféricas com as zonas rurais pode ser evidenciada pela comparação entre o dia mais frio e o mais quente no período das medições. No dia 07 de setembro de 2019 ocorreram as temperaturas mais baixas e, mesmo assim, o Centro apresentou uma diferença de até $5^{\circ} \mathrm{C}$ dos outros locais, os quais apresentaram medições de 25 a $26^{\circ} \mathrm{C}$, enquanto o Centro teve temperatura de 30 ${ }^{\circ}$ C. Já em São João e São Pedro Frio, as temperaturas máximas nesse dia foram de $26^{\circ} \mathrm{C}$ e $22.7^{\circ} \mathrm{C}$, respectivamente. O mesmo ocorreu no dia mais quente, 12 de setembro de 2019, porém a discrepância entre as medições foi ainda maior.

Enquanto Brotas, Marista e Ifes tiveram temperaturas entre $33.1^{\circ} \mathrm{C}$ e $35^{\circ} \mathrm{C}$, próximas às das áreas rurais que foram de $35.9^{\circ} \mathrm{C}$ no distrito Teresense e $32.5^{\circ} \mathrm{C}$ no distrito Colatinense, o Centro marcou $46.2^{\circ} \mathrm{C}$, cerca de $13{ }^{\circ} \mathrm{C}$ a mais que as outras áreas.

Além de áreas livres e arborizadas que contribuem para o conforto térmico, outras medidas podem ser tomadas para mitigar o problema, como o uso de cores mais claras e que refletem a luz nas fachadas das edificações, utilização de materiais construtivos porosos, como o concregrama que pode ser usado em calçadões para aumentar a permeabilidade do solo, a implantação de telhados verdes que podem diminuir a temperatura cerca de $9^{\circ} \mathrm{C}$. Além dessas medidas, podem ser feitos Planos Diretores Urbanos personalizados 
para cada zona da cidade, para atenderem às características morfológicas de cada região.

Diante do que foi analisado, a cidade de Colatina demonstrou desempenho térmico já esperado, apresentado também por Santos (2018) e Merigueti (2017), com o Centro se destacando com as maiores temperaturas e amplitudes térmicas, apresentando o problema das ilhas de calor.

\section{AGRADECIMENTOS}

Às nossas famílias que nos deram o apoio necessário para concluir o projeto.

Ao nosso orientador Prof. Alexandre Cypreste Amorim, que nos deu a oportunidade de pesquisar acerca deste assunto e sempre nos motivou ao caminho das ciências.

Às Prof. Karla Fiorot e Prof. Amabeli Dell Santo, que compartilharam conosco o conhecimento para elaborarmos a estrutura do trabalho.

Ao Ifes Campus Colatina, que nos proporcionou um ensino de qualidade, incitando-nos a pesquisar e estudar.

Por fim, às demais pessoas que durante essa caminhada nos auxiliaram de diversas formas, às quais seremos eternamente gratos, pois, apesar das dificuldades, conseguimos obter êxito.

\section{REFERÊNCIAS}

AMORIM, M. C. C. T. et al.

Características das ilhas de calor em cidades de porte médio: exemplos de Presidente Prudente (Brasil) e Rennes (França). Confins, n. 7, 2009. Disponível em: https://journals.openedition.org /confins/6070. Acesso em: 17 maio 2019.

AMORIM, Margarete Cristiane de Costa Trindade. Ilhas de Calor Urbanas: Métodos e Técnicas de Análise. Revista Brasileira de Climatologia, [S.1.], june
2019. ISSN 2237-8642. Disponível em: https://revistas.ufpr.br/revistaabclima/articl e/view/65136. Acesso em: 18 maio 2020. Doi http://dx.doi.org/10.5380/ abclima.v0i0 .65136.

ASSIS, E. S. et al. Aplicação de dados no clima urbano no desenvolvimento de planos diretores de cidades mineiras. In: ENCONTRO NACIONAL, 9., LATINO AMERICANO DE CONFORTO NO AMBIENTE CONSTRUIIDO, 5., 2007, Ouro Preto. Anais [...] Ouro Preto.

Disponível em: https://www.researchgate. net/publication/290436670 aplicacao de dados_do_clima_urbano_no_desenvolvime nto_de_planos_diretores_de_cidades_mine iras. Acesso em: 16 maio 2019.

ASSIS, Eleonora Sad de. A abordagem do clima urbano e aplicações no planejamento da cidade: reflexões sobre uma trajetória. In: Encontro Nacional De Conforto No Ambiente Construído, 8; Encontro Latino Americano De Conforto No Ambiente Construído, 6., 2005, Maceió. Anais [...], Maceió, 2005. Disponível em: http:// www.fau.usp.br/ arquivos/disciplinas /au/aut0225/Assis_2005_reflexoes_trajetor ia.pdf. Acesso em: 24 maio 2019.

BARROS, H.; LOMBARDO, M. A ilha de calor urbana e o uso e cobertura do solo no município de São Paulo-SP. GEOUSP

Espaço e Tempo, v. 20, n. 1, p. 160-177, 10 maio 2016. Disponível em:http://www. revistas.usp.br/geousp/article/view/97783. Acesso em: 16 maio 2019.

CARLOWICZ, M. Ecosystem, Vegetation Affect Intensity of Urban Heat Island Effect. Nasa. 15 dez. 2009. Disponível em: https://www.nasa.gov/mission_pages/terra/ news/heat-islands.html. Acesso em: 17 maio 2019.

\section{COELHO, André L. N. Bacia}

hidrográfica do Rio Doce (MG/ES): uma análise socioambiental integrada. Geografares, Espírito Santo, nº 7, 2009. Disponível em: http://periodicos.ufes.br 
/geografares/article/viewFile/156/82.

Acesso em: 19 maio 2019.

COELHO, André L. N. et al.

Mapeamento Geomorfológico do Estado

do Espírito Santo. Instituto Jones dos

Santos Neves. Vitória (ES), NT. 28, 2012.

Disponível em: http://www.ijsn.es.gov.br

/component/ attachments/download/1598.

Acesso em: 30 maio de 2019.

COLATINA. Colatina online, Geografia. Colatina. 2018. Disponível em: http:// www.colatina.es.gov.br/acidade/?pagina $=\mathrm{g}$ eografia. Acesso em: 17 out. de 2019.

COLATINA. Colatina online, A cidade. Colatina. 2018. Disponível em:

http://www.colatina.es.gov.br/acidade/?pag ina=cidade90. Acesso em: 19 nov. 2019.

FELLOWS, M. Utilizing New

Technologies to Update an Old Concept.

Nasa \& Green roof Research, Nova

Iorque, jul. 2012. Disponível em:

https://www.nasa.gov/sites/default/files/66

5642main_NASA_and_Green_Roof_Rese arch_Revised_9_6_2012.pdf. Acesso em: 19 maio 2019.

FROTA, A. B.; SCHIFFER, S. T. R. Manual de conforto térmico. 8. ed. São Paulo: Studio Nobel, 2003.

GARTLAND, L. Ilhas de calor: como mitigar zonas de calor em áreas urbanas. São Paulo: Oficina de Textos, 2010.

GOOGLE. Google Earth. 2019. Disponível em: https://earth.google.com/web. Acesso em: 14 nov. 2019.

IBGE. Cidades e Estados, Colatina. 2019. Disponível em: https://www.ibge. gov.br/cidades-e-estados/es/colatina.html Acesso em: 17 out. 2019.

IBGE. Cidades e Estados, Santa Teresa. 2019. Disponível em: https://www.ibge. gov.br/cidades-e-estados/es/santa-teresa. html. Acesso em: 17 out. 2019.
MERIGUETI, Julia Rodrigues. Avaliação Microclimática e o Fenômeno das Ilhas de Calor em Colatina-ES. Colatina:

REVISTA, 2017.

OKE, T. R; STEWART, I. D. Local climate zones for urban temperature studies. Vancouver, maio 2012.

Disponível em: https://journals.ametsoc. org/doi/pdf/10.1175/BAMS-D-11-00019.1. Acesso em: 19 maio 2020.

SANTA TERESA. Dados gerais. 2017. Disponível em: https://www.santateresa.es. gov.br/site/pagina/dadosgerais/105/2 Acesso em: 17 out. 2019.

SANTOS, Eloiza Baleeiro et al. Desenho de Paisagem: impacto no clima urbano e sensações de conforto em Colatina-ES. In: CONGRESSO INTERNACIONAL DE SUSTENTABILIDADE URBANA, 14., 2018, Vila Velha. Anais [...]. Vila Velha, 2018. Disponível em: https://nvdjjwjs2pz3 uphn0y3dmq-on.drv.tw/ciresurbenere/ arquivos/PDFs/SUSTENTABILIDADE $\% 2$ 0URBANA\%20_\%20PAG\%20425.pdf. Acesso em: 13 jun. 2019.

SILVA, J.F; FERREIRA, H. S; SANTOS, M. O. Considerações sobre os estudos em clima urbano. Revista Geama, v. 1, p. 162-175, 30 nov. 2015. Disponível em: http://www.journals.ufrpe.br/index.php/gea ma/article/view/536/1425. Acesso em: 19 maio 2019 .

SETZER, J. Atlas Climático e Ecológico do Estado de São Paulo. Comissão Interestadual da Bacia Paraná-Uruguai, 1966, 61p.

ZAMBORLINI, Felipe et al. Uma revisão sobre a controversa classificação da Floresta de Linhares, norte do Espírito Santo. Rodriguésia, Rio de Janeiro, vol. 68(5), 2017. Disponível em: http://www. scielo.br/scielo.php?script $=$ sci_arttext\&pid $=$ S2175-78602017000701987. Acesso em: 17 maio 2019. 